\title{
BROEKMANN, Theo, Rigor iustitiae. Herrschaft, Recht und Terror im normannisch-staufischen Süden (1050-1250)
}

Jean-Marie Martin

\section{OpenEdition}

Journals

Édition électronique

URL : http://journals.openedition.org/ifha/550

DOI : 10.4000/ifha.550

ISSN : 2198-8943

Éditeur

IFRA - Institut franco-allemand (sciences historiques et sociales)

Référence électronique

Jean-Marie Martin, «BROEKMANN, Theo, Rigor iustitiae. Herrschaft, Recht und Terror im normannischstaufischen Süden (1050-1250) », Revue de l'IFHA [En ligne], Date de recension, mis en ligne le 01 janvier 2007, consulté le 22 septembre 2020. URL : http://journals.openedition.org/ifha/550 ; DOI : https:// doi.org/10.4000/ifha.550

Ce document a été généré automatiquement le 22 septembre 2020.

(CIFHA 


\title{
BROEKMANN, Theo, Rigor iustitiae. Herrschaft, Recht und Terror im normannisch-staufischen Süden (1050-1250)
}

\author{
Jean-Marie Martin
}

Th.B. se recommande du courant de l'« anthropologie juridique ", qui s'attache à montrer comment, dans l'Occident médiéval, les conflits se résolvent normalement par un compromis : au terme d'un rituel de soumission de l'une des parties, l'autre lui accorde sa grâce. Cette attitude permet de tempérer la iustitia par la misericordia. L'intérêt d'une telle approche est évident ; elle tend toutefois à relativiser l'importance $\mathrm{du}$ droit et sous-entend que tout conflit mérite une solution plus politique que juridique.

Ce genre de compromis est vite banni de la pratique dans la Sicile normande. Après avoir présenté la porte frédéricienne du pont de Capoue, symbole du pouvoir absolu fondé sur le droit romain, Th.B. s'attaque à l'histoire politique de l'Italie et de la Sicile normandes ; si les ducs de Pouille acceptent de composer pour mettre fin aux conflits qui les opposent à l'aristocratie, le comte de Sicile ne mitige pas le rigor iustitiae en usant de miséricorde : il fait aveugler douze complices de son fils rebelle Jourdain. La terreur, qui a permis à Roger Ier d'asseoir son pouvoir, devient la règle de conduite de Roger II, fondateur du royaume en 1130 : tout en sacrifiant parfois en apparence à la pitié, il frappe avec rigueur l'aristocratie méridionale (son beau-frère Rainolf d'Alife) et les villes, au nom d'une idéologie qu'on ne rencontre pas en Angleterre avant le XIVe s. Pendant la minorité de Guillaume II, l'auteur montre l'opposition entre l'attitude du chancelier, d'origine française, Étienne du Perche, qui cherche le compromis, et la pratique locale (les consuetudines terrae) qui l'emporte et le force à partir. La pratique sicilienne est reprise par Henri VI et Frédéric II. On quitte alors la Sicile pour la Germanie avec la longue étude (une centaine de pages) du conflit entre l'empereur Frédéric II et son fils Henri VII, roi de Germanie, brutalement privé de son honor par 
son père et emprisonné en Calabre jusqu'à sa mort. Th.B. présente le contexte germanique, l'attitude du roi vis-à-vis de l'aristocratie (partiellement associée au pouvoir), exposée dans une lettre à l'évêque d'Hildesheim. En 1235, Frédéric arrive en Allemagne, son fils accomplit le rituel de soumission, mais la grâce paternelle lui est refusée. Le chroniqueur anglais Matthieu Paris doit inventer une tentative d'empoisonnement du père par le fils pour expliquer une attitude qu'il ne peut comprendre.

Les analyses textuelles de l'auteur sont souvent justes et fines et font bien ressortir l'originalité sicilienne - ce qui ne constitue pas une nouveauté absolue. On regrette que les sources utilisées soient toutes littéraires : les actes royaux et la législation sont pratiquement absents. En outre Th.B. étudie les rapports du souverain avec la « noblesse » et avec les villes, sans chercher à définir ces deux partenaires du pouvoir ; or l'aristocratie se forme au XIe s. Quant aux villes méridionales, elles n'ont connu que de très brèves périodes d'autonomie. La faiblesse de l'épiscopat du Royaume est justement dénoncée, mais il ne faut pas oublier le rôle politique de premier plan joué au XIIe s. par certains prélats siciliens. Au total, l'auteur connaît assez mal certaines réalités suditaliennes (et une partie de la bibliographie) : les princes lombards sont qualifiés de ducs, le duc de Naples (successeur de fonctionnaires byzantins) est pris pour un duc lombard, le catépanat d'Italie est devenu un « Kapitanat von Apulien » (p. 25-28). À l'époque de Roger II, Bénévent, enclave pontificale, ne peut être traitée comme une ville du Royaume. Enfin Th.B. ne tire pas de ses analyses la conclusion qui s'impose : la Sicile, peuplée d'Arabes et de Grecs, n'appartient pas, politiquement, au monde occidental. Il en est de même pour le royaume constitué par Roger II, dont la base la plus ferme est une bureaucratie arabe et grecque. Enfin, la juxtaposition de deux sujets (la Sicile des XIe-XIIe s. et la Germanie du XIIIe) et la lenteur des démonstrations ne facilitent pas la lecture d'un livre qui aborde un vrai problème.

Jean-Marie MARTIN (Centre National de la recherche Scientifique/ École française de Rome) 